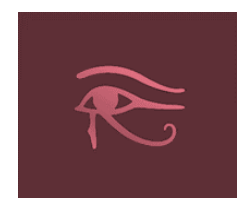

\title{
AS TECNOLOGIAS DIGITAIS DA INFORMAÇÃO E DA COMUNICAÇÃO NOS CONTEXTOS DA EDUCAÇÃO DE JOVENS E ADULTOS: UMA REVISÃO DE LITERATURA (2007-2014)
}

\author{
Bruno dos Santos Joaquim \\ brunosjoaquim@hotmail.com
}

Lucila Pesce

lucilapesce@gmail.com

\author{
Universidade Federal de São Paulo
}

RESUMO: O presente artigo pretende realizar uma revisão da literatura acadêmica produzida entre os anos de 2007 e 2014 sobre o uso pedagógico das Tecnologias Digitais da Informação e da Comunicação (TDIC) em contextos relacionados à Educação de Jovens e Adultos (EJA), no Brasil. A partir de critérios definidos, foram selecionados 14 trabalhos de diversas universidades do país, cujo objeto de investigação aloca-se na intersecção de dois campos: EJA e uso pedagógico das TDIC. Os estudos apresentam três grandes tendências: a) o apontamento para a escassez de trabalhos preocupados em investigar o impacto das tecnologias no campo da EJA; b) a preocupação dos autores em ressaltar as potencialidades do uso das TDIC na aprendizagem e na inclusão digital de jovens e adultos; c) a indicação da necessidade de se promover formação específica de professores da EJA para o uso das tecnologias.

PALAVRAS-CHAVE: Educação de Jovens e Adultos; Tecnologias Digitais da Informação e Comunicação (TDIC); Inclusão Digital.

\section{THE DIGITAL TECHNOLOGIES OF INFORMATION AND COMMUNICATION IN THE CONTEXT OF YOUTH AND ADULT EDUCATION: A LITERATURE REVIEW (2007-2014)}

\begin{abstract}
This paper makes a review of the academic literature produced between 2007 and 2014, on the pedagogical use of Digital Information and Communication Technologies (TDIC) in contexts related to Youth and Adult Education (EJA) in Brazil. From defined criteria, it were selected 14 studies from various universities in the country, whose research's object is located at the intersection between two fields of investigations: adult education and the pedagogical use of TDIC. The studies have three major trends: a) pointing to the lack of studies concerned with investigating the impact of technology in adult education; b) the concern of authors highlight the potentiality of the use of TDIC in digital learning and inclusion of young people and adults; c) an indication of the need to promote specific training of adult education teachers to the use of technology.

KEYWORDS: Youth and Adult Education; Digital Technologies of Information and Communication (TDIC); Digital Inclusion.
\end{abstract}




\section{Introdução}

O presente artigo propõe-se a realizar uma revisão da literatura acadêmica produzida no septênio 2007-2014 sobre o uso pedagógico das Tecnologias Digitais da Informação e da Comunicação (TDIC) em contextos relacionados à Educação de Jovens e Adultos (EJA), no Brasil. A pertinência do tema está relacionada à escassez de trabalhos situados no espaço de intersecção entre os campos da educação, linguagem e comunicação, especialmente, as pesquisas sobre o uso pedagógico das TDIC e o campo da pesquisa sobre EJA no Brasil, suas políticas, práticas e sujeitos.

A partir da busca pelos descritores "tecnologias digitais da informação e da comunicação (TDIC)", "tecnologias da informação e da comunicação", "educação de jovens e adultos (EJA)" e "inclusão digital”, nos principais bancos de teses, dissertações e artigos científicos, como banco de teses e dissertações da Coordenação de Aperfeiçoamento de Pessoal de Nível Superior (CAPES), Domínio Público, o indexador de publicações acadêmicas Scientific Electronic Library Online - SciELO, anais das reuniões da Associação Nacional de Pós-Graduação e Pesquisa em Educação - ANPEd e na plataforma de busca Google Acadêmico, foram selecionadas, a partir da análise de seus resumos, 14 pesquisas acerca do uso de novas tecnologias na EJA, que foram lidas na íntegra.

Três tendências foram observadas através desta revisão de literatura: a) há poucos estudos sobre a formação de professores para o uso das TDIC no contexto da EJA; b) há consenso entre os autores de que o uso pedagógico das TDIC na EJA contribui positivamente para o processo de ensino-aprendizagem dos alunos adultos e contribui para sua emancipação, como sujeitos e enquanto classe; c) os estudos apresentados indicam que, mais do que nunca, é necessário superar a perspectiva técnica e instrumental na integração das TDIC às práticas escolares e substituí-la por uma visão mais crítica, reflexiva e que se ampare na constituição do professor, como profissional da educação que pode desempenhar sua função, erguido em meio à perspectiva autoral.

Com o objetivo de situar esta pesquisa bibliográfica em meio a dois campos distintos da pesquisa educacional é importante que sejam traçadas e imbricadas reflexões sobre o uso pedagógico das TDIC e sobre a educação de jovens e adultos no Brasil. A fusão dos dois olhares é necessária, uma vez que não há ainda grande mobilização de pesquisadores do campo das tecnologias educacionais para refletir sobre sua temática no contexto específico da educação de pessoas jovens e adultos, da mesma forma como não é prioridade dos pesquisadores do campo da educação de jovens e adultos a investigação 
sobre os limites e as possibilidades do uso pedagógico das TDIC e da inclusão digital, nesta modalidade escolar. Ambos são campos que ocupam espaços secundários nas políticas públicas e na pesquisa educacional, mas que estão diretamente relacionados à noção da educação como um direito fundamental, com vistas ao pleno exercício da cidadania. E mais, ambos passam por um lento processo de mudança de paradigma, motivados por novas tendências, em seus campos de reflexão pedagógica.

\section{A Educação de Jovens e Adultos no Brasil: superar o paradigma compensatório}

Entre os principais entraves que dificultam o bom desenvolvimento da educação de jovens e adultos no Brasil, está a predominância da noção compensatória, presente em todo desenvolvimento histórico da modalidade. Esta visão está ligada à concepção de ensino supletivo, isto é, a reposição de estudos não realizados na infância e na adolescência.

Ao dirigir o olhar para a falta de experiência e conhecimento escolar dos jovens e adultos, a concepção compensatória nutre visões preconceituosas que subestimam os alunos, dificulta que os professores valorizem a cultura popular e reconheçam os conhecimentos adquiridos pelos educandos no convívio social e no trabalho (DI PIERRO, 2005, p.1118).

A história da EJA no Brasil é marcada por uma trajetória de abandono, indefinição, improviso e é representativa da própria constituição do país, como portador de uma estrutura social desigual. A lógica da compensação remonta à própria história de formação de uma educação destinada a pessoas adultas no Brasil. Durante o Estado Novo, quando o investimento na alfabetização de adultos representava todo um projeto de formação de mão de obra urbano-industrial nos grandes centros do país, a Campanha de Educação de Adultos Analfabetos (CEAA), coordenada por Lourenço Filho e implantada a partir de 1947, já consolidava uma visão centrada na compensação da ausência. O adulto analfabeto ou pouco escolarizado era entendido como um sujeito incapaz de decidir por si mesmo, nas diversas esferas da vida social. 'Projetava-se a imagem da 'criança grande', que de forma deficiente desempenharia suas responsabilidades familiares e profissionais". (FREITAS e BICCAS, 2009, p. 221)

Apesar da perspectiva preconceituosa sobre o adulto analfabeto, a CEAA foi responsável por colocar a educação de jovens e adultos na agenda das políticas educacionais de responsabilidade do Estado e instaurar no país um novo campo de reflexão pedagógica. No contexto da década de 1950 e início da década seguinte, o 
discurso do desenvolvimento e da constituição de uma sociedade moderna estava vinculado à qualificação do trabalhador para atender às necessidades advindas do progresso. Deste cenário advém uma perspectiva renovadora de educação de adultos, que se contrapunha ao discurso hegemônico. As ideias de Paulo Freire voltam-se à defesa de ações direcionadas à formação da consciência crítica do cidadão, do ponto de vista individual e coletivo, especialmente a população mais pobre, historicamente excluída do pleno exercício de sua cidadania (FREITAS e BICCAS, 2009).

$\mathrm{Na}$ efervescência das propostas de Paulo Feire, que ganhavam corpo nas mais diferentes experiências de educação popular do início da década de 1960, residia uma educação concebida como "constructo que se estrutura pela própria cultura, mais especificamente pela cultura popular, partindo sempre dos conhecimentos prévios do povo" (FREITAS e BICCAS, 2009, p. 234). Diante de tudo o que o movimento representou, o período de 1959 e 1964 é considerado o período das luzes para a educação de jovens e adultos (RESENDE, 2008). Este projeto, no entanto, sofre uma profunda ruptura com o Golpe Militar de 1964, que resulta na repressão e desmantelamento dos programas de educação popular e no retrocesso radical da concepção de educação de adultos.

Durante o Regime Militar, a educação de jovens e adultos passa a ocupar um importante lugar no processo de mediação entre o Estado, tomado por um projeto de desenvolvimento econômico aliado ao controle social, e a sociedade brasileira. Ela foi um dos instrumentos que possibilitaram a coerção social e foi projetada como um símbolo “democrático" em um país que passava por um regime de 'exceção' (FREITAS e BICCAS, 2009). As principais ações do Regime Militar no campo da educação de adultos foram o Movimento Brasileiro de Alfabetização (Mobral), criado em 1967 com o objetivo de fazer frente às elevadíssimas taxas de analfabetismo no país, e a regulamentação do ensino supletivo, através da Lei n. 5692, de 1971. Trata-se da retomada da responsabilidade do Estado em promover a escolarização de adultos, porém a partir de uma perspectiva que se propunha "a recuperar o atraso, a reciclar o presente formando uma mão-de-obra que contribuísse no esforço para o desenvolvimento nacional, através de um novo modelo de escola" (HADDAD e DI PIERRO, 2000, p. 117). A lógica da compensação, mais uma vez, passa a ser o mote da educação de pessoas adultas, na medida em que não é dada nenhuma atenção especial ao preparo de material didático adaptado, formação de professores ou reflexões sobre estratégias didáticas específicas para os cursos supletivos. 
As tecnologias digitais da informação e da comunicação nos contexto da Educação de Jovens e Adultos: uma revisão de literatura (2007-2014)

O modelo proposto pelo ensino supletivo, que atendia ao apelo tecnicista e compensatório, se manteve mesmo após a promulgação da Lei de Diretrizes e Bases da Educação, n. 9394, de 1996 (BRASIL). A cultura educacional brasileira continua impregnada pela concepção compensatória de educação de jovens e adultos, que ainda é vista como um instrumento de reposição de estudos não realizados na infância ou adolescência (DI PIERRO, 2005). O processo de redemocratização do país trouxe algumas experiências que recuperam o legado dos movimentos de educação popular, mas ainda representam tímidas iniciativas, diante da compreensão geral que se tem da EJA.

Hoje, a superação do paradigma compensatório apresenta-se como uma das necessidades mais urgentes para o avanço qualitativo da EJA no Brasil. Acrescenta-se a esse desafio, a necessidade de investimentos na formação específica de professores, a formulação de políticas públicas direcionadas ao atendimento da enorme demanda de adultos com baixa escolaridade e a sua consolidação, como um campo da pesquisa educacional.

Se o direito à educação ultrapassar a oferta de uma segunda oportunidade de escolarização, ou na medida em que esses milhões de jovens-adultos forem vistos para além dessas carências. Um novo olhar deverá ser construído, que os reconheça como jovens e adultos em tempos e percursos de jovens e adultos. Percursos sociais onde se revelam os limites e possibilidades de ser reconhecidos como sujeitos dos direitos humanos. (ARROYO, 2005, p. 23)

A superação do paradigma compensatório está, neste sentido, diretamente ligada à concepção de educação como direito e de educação ao longo da vida. Esta nova perspectiva, que ganha força internacional através da V Conferência Internacional de Educação de Adultos (CONFINTEA), realizada em Hamburgo no ano de 1997, tem provocado na última década uma lenta mudança neste quadro, de modo que a EJA começa a ser compreendida como um direito de todos à educação ao longo da vida.

O conceito de educação ou aprendizagem ao longo da vida é polissêmico e objeto de disputa entre os teóricos que defendem uma perspectiva de formação humanística, voltada à formação integral e à emancipação, e os organismos nacionais e internacionais, que se apropriam do conceito para planejar e implantar políticas públicas de formação profissional, a partir de uma perspectiva instrumental. Em sua essência, o conceito de aprendizagem ao longo da vida inclui diversas esferas, como o desenvolvimento pessoal ao longo dos ciclos de vida, a aquisição de competências laborais, o manejo de tecnologias, a aprendizagem de línguas e de relações multiculturais, a socialização política e a participação cidadã (TORRES, 2003). 
Para, além da construção conceitual do chamado lifelong learnig, o que este novo paradigma traz de transformador é a compreensão da EJA como um direito de todos. É a perspectiva da EJA como direito que incide diretamente nas pesquisas analisadas nesta revisão de literatura. Os trabalhos sobre o uso de tecnologias em práticas educacionais em contextos de educação de jovens e adultos representam esta transformação de perspectiva. Da mesma forma, a concepção de tecnologia adotada nestes estudos representa, por sua vez, também uma mudança de paradigma, quando as TDIC não são mais compreendidas em sua perspectiva instrumental, mas a partir de um olhar crítico.

\section{As Tecnologias Digitais da Informação e da Comunicação na educação: superar o paradigma instrumental}

A superação do paradigma instrumental das TDIC na educação depende primeiramente da compreensão de que "a tecnologia per se não parece garantir sucesso no aprendizado." (LAVINAS e VEIGA, 2013, p.3). Brito (2006) entende que o professor deve se desvincular da ideia de tecnologia como objeto ou ferramenta para que "entenda a tecnologia como instrumento de intervenção na construção da sociedade democrática, contrapondo-se a qualquer tendência que o direcione ao tecnicismo, a coisificação do saber e do ser humano" (BRITO, 2006, p.14). O impacto transformador das TDIC na EJA e na educação como um todo, só é possível se estiver em confluência com a criação de novas metodologias, formação de professores para seu uso educacional e não meramente instrumental e políticas públicas que garantam infraestrutura para as escolas.

A necessidade de propor esta superação parece fundamental, já que o apelo da sociedade capitalista é pela incorporação das TDIC, sob a égide de uma racionalidade técnica e instrumental (ADORNO e HORKHEIMER, 1985). De acordo com Adorno e Horkheimer (1985), a perspectiva crítica é a premissa para o rompimento com esta racionalidade que, ao mesmo tempo em que foi fundante de um avanço tecnológico muito veloz, não se relaciona à concepção de educação como direito. Segundo Valente (2002), a internet pode "revolucionar as abordagens educacionais tradicionais; ou ser utilizada para complementar ou subsidiar os processos de transmissão de informação que ainda persistem na grande maioria das escolas" (VALENTE, 2002, p. 132). O impacto transformador das TDIC na educação só será viável se estiver em confluência com a formação de professores para seu uso educacional, abrangendo todas as suas 
As tecnologias digitais da informação e da comunicação nos contexto da Educação de Jovens e Adultos: uma revisão de literatura (2007-2014)

possibilidades de transformação e emancipação dos sujeitos, e não seu uso meramente instrumental.

Ao refletir sobre a formação inicial de professores para o uso das TDIC, Pesce (2014) afirma que

Cada vez mais, o frenesi das atuais organizações societárias banaliza os espaços sociais nos quais os seres humanos se constituem como sujeitos históricos. Esse torpor também se faz presente nos espaços educacionais e na utilização pedagógica das TIC, em três instâncias: quando esta área de formação docente colabora com a coisificação do homem, ao se restringir à mera instrumentalização para a fluência tecnológica; quando esta área de formação vai de encontro à emancipação humana, ao deixar de tematizar as contradições inerentes às TIC, como todo e qualquer aparato simbólico apropriado pelo capital; quando esta área de formação assume um caráter pragmático, ao voltar sua atenção para as questões gnosiológicas, sem auferir igual importância às questões ontológicas, nelas inclusa a relação entre a construção social do tempo e a constituição das identidades dos sujeitos sociais contemporâneos. O trabalho na área de formação docente para o uso pedagógico das TIC, tomado nesta esfera restrita, corrobora com o entusiasmo ingênuo para com a inserção das TIC na Educação e, por conseguinte, contribui com a apropriação acrítica do recurso tecnológico, pelo espaço escolar (PESCE, 2014, p. 167-8).

Desta forma, fica claro que o caminho para a superação da perspectiva instrumental na direção de uma visão crítica do uso das TDIC passa necessariamente pela formação de professores. Entre as pesquisas analisadas nesta revisão bibliográfica, alguns estudos, como os de Cruz (2008), Nápoles (2008), Flôres (2011) e Fernandes (2012), apontam para a necessidade de repensar a formação inicial e continuada de professores para o uso das TDIC.

Sem dúvida, as tecnologias podem ser novos e muito úteis meios de construir e difundir conhecimentos sem risco de desumanizar o ser humano. Tudo depende do modo como as utilizamos: se nos apropriamos de seu potencial pedagógico e comunicacional e as colocamos a serviço do homem ou se, ao contrário, nos deixamos dominar por elas, transformando-nos em consumidores de gadgets concebidos para um mercado de massa planetário. (BELLONI, 1998, p. 255)

Para Giroux (1997), "uma das maiores ameaças aos professores é o desenvolvimento crescente de ideologias instrumentais que enfatizam uma abordagem tecnocrática para a preparação dos professores e também para a pedagogia de sala de aula." (GIROUX, 1997, p.158). Esta postura crítica é fundamental para que, do ponto de vista político, os professores tenham condições de se apropriar da cibercultura, das mídias e das tecnologias digitais, compreendendo-as como possibilidades de produção e compartilhamento de conhecimento e informação com o objetivo de situá-los numa perspectiva autoral. 
A perspectiva de inclusão digital e de uso pedagógico das TDIC, apresentada pelas pesquisas desta revisão de literatura, estão relacionadas à ideia de empoderamento, na acepção freireana do termo, de acordo com Pesce (2013). A inclusão digital, se promovida em seu sentido emancipador, pode ser elemento facilitador da educação libertadora, por oferecer ao socialmente excluído o acesso à cultura digital e suas potencialidades de exercício da cidadania. Neste sentido, ela pode contribuir para aquilo que Paulo Freire, em diálogo com Ira Shor, em Medo e Ousadia - o cotidiano do professor (1986), chama de empowerment (empoderamento).

Empowerment configura-se como um processo de tomada de consciência coletiva que se dá na interação entre indivíduos e envolve, em certa medida, um desequilíbrio nas relações de poder na sociedade. Trata-se do empoderamento de classe social. "Não individual, nem comunitário, nem meramente social, mas um conceito de empowerment ligado à classe social" (FREIRE; SHOR, 1986, p. 72).

De acordo com Pesce (2013), Paulo Freire considera que a educação seja o caminho para o empoderamento da classe trabalhadora. Ele destaca o "papel fulcral da Educação, para promover práticas sociais contribuintes da construção do capital cultural de grupos, cuja cultura socialmente legitimada ainda não tenha sido incorporada" (PESCE, 2013, p.5-6).

A inclusão digital na educação de jovens e adultos, se configurada como ação cultural para libertação, poderá ter um impacto profundo na vida social dos sujeitos adultos reinseridos no espaço escolar. Isto só será viável, no entanto, se a educação de jovens e adultos for compreendida a partir de uma perspectiva não compensatória, que tenha por base o sentido pleno de educação ao longo da vida. Se dotada desta significação, ela permitirá reconhecer os sujeitos adultos como dotados da capacidade de aprender, de se incluir, social e digitalmente e, portanto, de se empoderar.

\section{As pesquisas sobre as Tecnologias Digitais da Informação e Comunicação nos contextos da Educação de Jovens e Adultos (2007-2014)}

Através de busca nos principais indexadores de trabalhos acadêmicos foram selecionados 14 estudos sobre as TDIC nos diferentes contextos da Educação de Jovens e Adultos, publicados entre o septênio 2007 e 2014. O ano de 2007 serve de marco para este recorte temporal, por ser o ano de promulgação da lei 11.494/2007, que cria o Fundo de Manutenção e Desenvolvimento da Educação Básica e de Valorização dos 
As tecnologias digitais da informação e da comunicação nos contexto da Educação de Jovens e Adultos: uma revisão de literatura (2007-2014)

Profissionais da Educação (FUNDEB), que entra em vigor, em substituição ao Fundo de Manutenção e Desenvolvimento do Ensino Fundamental e Valorização do Magistério (FUNDEF). O FUNDEB foi celebrado principalmente pelos setores educacionais (níveis e modalidades) alijados anteriormente do FUNDEF, principalmente a Educação Infantil, o Ensino Médio e a Educação de Jovens e Adultos (EJA). O reconhecimento da existência da EJA na distribuição de recursos da União, ainda que aquém da real necessidade e demanda da modalidade, impactou positivamente na visibilidade da EJA ante as políticas públicas (GOUVEA, 2008) e pode apresentar desdobramentos, para os estudos e pesquisas desenvolvidas no campo.

A dissertação de Goulart (2007), "Inclusão digital na terceira idade: a virtualidade como objeto e reencantamento da aprendizagem", da Universidade Federal de São Carlos (UFSCar), objetiva compreender o que motiva pessoas da terceira idade a procurar por cursos de inclusão digital e constata que o idoso, mesmo com as perdas decorrentes do avanço de sua idade, possui potencialidades para continuar aprendendo e que estar incluído na cultura digital é bastante significativo para os participantes da pesquisa. Os dados coletados em um curso de inclusão digital para a terceira idade em Porto Alegre, Rio Grande do Sul, apontam para a necessidade urgente de inserção deste grupo na cultura digital. Ainda que este trabalho não se relacione diretamente com a escolarização, é relevante para o debate, na medida em que serve para demonstrar a existência da demanda por inclusão de pessoas adultas no mundo digital, reconhecendo o ciberespaço como espaço de exercício da sociabilidade e cidadania.

“A educação de jovens e adultos no município de Curitiba sob a ótica de gênero e tecnologia”, de Hidalgo (2007), procura caracterizar a EJA nas escolas municipais, sob a perspectiva dos estudantes frente a questões de gênero e tecnologia. Seu objetivo é identificar os motivos que levam homens e mulheres a retomar seu processo de escolarização e conhecer as relações de gênero presentes no espaço escolar. A temática da tecnologia perpassa transversalmente a pesquisa, pois aparece durante as entrevistas com os jovens e adultos como um fator decisivo em seu interesse em retornar à escola. Segundo a autora, este dado trouxe a necessidade de incluir em sua pesquisa o objetivo de conhecer as percepções que os alunos atribuem à tecnologia. Apesar de a questão tecnológica ser secundária neste trabalho, ela se aproxima da perspectiva de EJA como direito, na medida em que o pesquisador da Universidade Tecnológica Federal do Paraná compreende a EJA como um caminho para empoderar os sujeitos com a tecnologia da 
leitura e da escrita, o que possibilita sua inclusão. É possível, em análise, encontrar uma aproximação entre sua análise de resultados e a noção de empoderamento freireano.

A dissertação "O uso do computador, a alfabetização e a pós-alfabetização: o que dizem educandos/as do MOVA”, pesquisa em nível de mestrado de Gonçalves (2007) da Pontifícia Universidade Católica do Rio Grande do Sul, objetiva analisar as contribuições da utilização do computador para a alfabetização e pós-alfabetização de jovens e adultos e para a superação da autoproteção através da fala dos educandos. O trabalho constata os benefícios do uso do computador na aquisição da leitura e da escrita na escolarização de jovens e adultos e aponta para a possiblidade de seu uso na emancipação dos sujeitos na Sociedade da Informação. Para indicar estes resultados, a autora se embasa no conceito de aprendizagem dialógica de Paulo Freire e tece seus argumentos, no sentido de valorizar as contribuições do uso da tecnologia nos processos de escolarização para o que chama de emancipação digital. Esta ideia coaduna-se com o conceito de empoderamento freireano, na medida em que emancipação digital é compreendida como a conquista da autonomia, a partir de uma perspectiva crítica, o que ultrapassa, deste modo, o conceito de inclusão digital, mais ligado a uma perspectiva de domínio instrumental das tecnologias.

Gontijo e Oliveira (2008) apresentaram o artigo "Vozes docentes e discentes sobre condições, objetivos e contribuições do uso das TIC na EJA” no I Seminário Nacional de Educação Profissional e Tecnológica do Centro Federal de Educação Tecnológica, em Belo Horizonte, Minas Gerais, que analisa a utilização das tecnologias em termos de condições de uso, objetivos e contribuições que têm para alunos e professores da EJA, através do mapeamento da presença da temática na produção da área e uma revisão teórica da produção acadêmica que aborda as TDIC nos processos socioeducacionais em curso. As autoras reforçam em sua revisão de literatura a existência de poucos estudos, em âmbito nacional e internacional, que focalizam a utilização das TDIC na EJA. Problematizam o delineamento de uma possível dupla marginalização na área: marginalização dessa modalidade de ensino das políticas que visam à introdução das TDIC nas escolas e marginalização das TDIC nas políticas voltadas para a EJA no país.

Santos (2008), ao investigar como pensa, interage e faz uso das TDIC o imenso contingente de população não alfabetizada da Bahia, traz uma análise bastante perspicaz das narrativas da história de vida de trabalhadores da construção civil não escolarizados ou de baixa escolaridade, que estão presentes em cursos de alfabetização e letramento oferecidos nos canteiros de obras. Sua dissertação "Tá vendo aquele edifício, moço? - A 
As tecnologias digitais da informação e da comunicação nos contexto da Educação de Jovens e Adultos: uma revisão de literatura (2007-2014)

especificidade da inclusão digital para trabalhadores da construção civil não alfabetizados", apresentada para obtenção do título de mestre pela Universidade Federal da Bahia, tem como objetivo identificar como se encontra o trabalhador, que não foi alfabetizado na leitura e escrita em língua portuguesa e que agora demanda por letramento digital para o pleno exercício de sua cidadania. Santos (2008) associa a inclusão digital ao processo de conquista da autonomia e exercício pleno da cidadania e alerta para o risco das tecnologias serem utilizadas como argumento para uma possível exclusão ou incapacidade atribuída a jovens e adultos não alfabetizados, para lidar com os recursos da informação e da comunicação. Os resultados da pesquisa revelam que as salas de aula implantadas nos canteiros de obras seguem uma proposta didática centrada no analógico e não alcançam a efetividade digital demandada pelos trabalhadores-alunos.

Entre os artigos, dissertações e teses coletados, o trabalho de Cruz (2008), do Centro Federal de Educação Tecnológica de Minas Gerais, merece destaque, pelo fato de apresentar em sua conclusão a constatação da necessidade de se ampliar o tempo e o espaço para a formação de professores para o uso das TDIC. A dissertação "Limites e possibilidades das tecnologias na educação de jovens e adultos" identifica as possíveis contribuições do uso das tecnologias na educação de jovens e adultos no processo de ensino e aprendizagem de uma escola que possui boas condições materiais para sua implantação. A autora parte do pressuposto de que as tecnologias são variáveis das relações de poder na sociedade contemporânea e, diante disso, ter seu domínio é uma questão de fortalecimento do sujeito frente à dinâmica social. A partir da observação participante, análise documental, questionários e entrevistas realizadas com professores e alunos, Cruz (2008) constata que a utilização das TDIC é ainda incipiente, mesmo em uma escola bem equipada. Percebe também que a ausência de tempo e espaço para o aprimoramento docente é um limite imponente ao uso das tecnologias em salas de aula da EJA, mas que a formação adequada permite que os docentes avancem em suas práticas pedagógicas, resgatando a infraestrutura tecnológica de maneira criativa e significativa. Sua conclusão, Cruz (2008) denuncia o descompromisso com a formação de professores para o uso das TDIC, o que é, para ele, um empecilho para o avanço neste campo, mesmo em escolas com acesso a elas.

As conclusões da pesquisa de Nápoles (2008), também do Centro Federal de Educação Tecnológica de Minas Gerais, em aderência à análise de Cruz (2008), apontam o despreparo dos professores quanto ao uso pedagógico das TDIC, em sua dissertação " $\mathrm{O}$ uso das tecnologias da informação e comunicação na educação de jovens e adultos: visão 
de alunos e professores de uma escola municipal de Belo Horizonte". O estudo de caso, cujo objetivo é investigar a percepção que discentes e docentes de uma escola municipal de ensino médio na modalidade EJA possuem sobre as TDIC, observou a utilização do laboratório de informática da escola e entrevistou alunos e professores. A autora percebeu o subaproveitamento do laboratório de informática, especialmente pelos professores, que, segundo ela, não estão adequadamente capacitados para o uso das tecnologias de uma forma inovadora, pois apenas reproduzem suas práticas de sala de aula com o uso da ferramenta, partindo, portanto, de uma perspectiva instrumental. Quanto à percepção que discentes e docentes fazem das TDIC, o estudo aponta que elas são consideradas essenciais para o desenvolvimento das aptidões necessárias à autonomia do cidadão. É possível afirmar que, mais uma vez, o conceito de empoderamento freireano está subscrito e que a formação adequada de professores para o uso pedagógico das TDIC é consensualmente mais que urgente.

Na mesma direção e sob a mesma perspectiva de Cruz (2008) e Nápoles (2008), e também com filiação acadêmica ao mesmo Centro Federal de Educação Tecnológica, a dissertação "Tecnologias de informação e de comunicação na educação de jovens e adultos" de Gontijo (2008), objetiva contribuir para a compreensão do uso das TDIC na educação de pessoas jovens e adultas. A pesquisa procura identificar a natureza da formação de professores para o uso das tecnologias na EJA, além das condições em que professores usam ou deixam de usá-las em suas práticas pedagógicas. A partir de uma pesquisa teórica e empírica, baseada nas entrevistas de discentes, docentes e coordenação do laboratório de informática de uma escola municipal de Belo Horizonte, Minas Gerais, a autora sugere que professores e alunos consideram as TDIC uma inovação no contexto da EJA, mas se apropriam delas de formas diferentes. Conclui que o uso das TDIC contribui para o aumento da autoestima dos alunos e para a redução das taxas de flutuação da frequência de alunos. Além disso, a pesquisadora identifica uma perspectiva fortemente instrumental na formação dos professores para o uso das TDIC, na medida em que o uso das tecnologias na escola projeta-se para o nível da alfabetização digital, isto é, o domínio incipiente e instrumental das tecnologias, distante da perspectiva crítica, fundamental para o processo de empoderamento e conquista da autonomia. Entre os apontamentos finais, Gontijo (2008) também indica a necessidade urgente de pesquisas no campo da formação de professores e gestores para a incorporação das TDIC nas práticas escolares. 
As tecnologias digitais da informação e da comunicação nos contexto da Educação de Jovens e Adultos: uma revisão de literatura (2007-2014)

Brito (2010), em sua dissertação “Jovens e Adultos em processo de escolarização e as tecnologias digitais: quem usa, a favor de quem e para quê?”, apresentada para obtenção do título de mestre em educação pela Universidade de São Paulo, realiza entrevistas com alunos da modalidade EJA, em escolas públicas de São Paulo, com o objetivo de investigar a presença das tecnologias na EJA, por meio dos usos que estudantes dizem fazer desses recursos e as possíveis relações desses usos com o processo de escolarização e as aprendizagens que vivenciam. A maior parte dos alunos, segundo o trabalho, faz uso das TDIC fora das escolas para se divertir, se comunicar e aprender sobre temas de seu interesse. A autora aponta para o fato de que, quanto mais escolarizados, mais os sujeitos se apropriam das tecnologias, na medida em que o seu uso depende muitas vezes de saberes prévios aprendidos na escola. $\mathrm{O}$ foco central deste trabalho está no sentido que os alunos dão às tecnologias e ao uso que dizem fazer do computador. Em sua conclusão, a autora destaca as variadas percepções que estes alunos tem sobre o uso das tecnologias e considera a inserção destes sujeitos na cultura digital um caminho necessário para o exercício pleno da cidadania.

A dissertação de mestrado de Coelho (2011), da Universidade Federal da Bahia, intitulada "As relações dos alunos da EJA com as tecnologias digitais: implicações e possibilidades na vida de cada um" investiga uma escola na cidade de Salvador, que faz uso das tecnologias em todas as fases de escolarização, a partir da perspectiva de que não é mais possível alfabetizar ou escolarizar ignorando as dinâmicas, concepções e tecnologias que norteiam os processos sociais contemporâneos. Seu objetivo é investigar e analisar como se dão as relações dos alunos da EJA com as tecnologias digitais e de quais formas eles ressignificam seus saberes e compreensão de mundo, a partir dessas relações. Através dos dados obtidos com entrevistas e observações do uso do laboratório de informática da escola, Coelho (2011) conclui que o uso das tecnologias altera a visão de mundo dos alunos da EJA e o seu cotidiano em casa e no trabalho. As TDIC na educação contribuem significativamente também para elevar a autoestima deles, para adquirirem confiança de que também são capazes de se apropriar dessas tecnologias e passar a usá-las de forma autônoma, isto é, as TDIC na educação situam-se como um instrumento de empoderamento e inclusão de jovens e adultos no exercício pleno da cidadania.

O trabalho de Flores (2011), por sua vez, investiga as práticas de professores da EJA que norteiam o ensino e aprendizagem da leitura e da escrita através do uso da TV e do computador como ferramentas sociais e de aprendizagem. O estudo de caso, intitulado 
“O uso da TV e do computador nas práticas docentes de Língua Portuguesa na educação de jovens e adultos", observou e entrevistou alunos e professores de ensino fundamental na modalidade EJA em uma escola municipal e outra estadual de Maceió, Alagoas. Assim como outros autores, o pesquisador da Universidade Federal de Alagoas também adverte para o uso ainda muito incipiente dessas tecnológicas na disciplina de Língua Portuguesa na EJA das escolas investigadas e reconhece que os professores necessitam de maior capacitação para conhecer e saber utilizar as múltiplas estratégias que a TV e o computador podem oferecer para o processo de ensino-aprendizagem, ainda que reconheçam a importância das tecnologias na integração das pessoas no meio social e no trabalho, para a educação e dinamização das suas estratégias pedagógicas. Se forem utilizadas adequadamente pelos profissionais da educação, as tecnologias conseguem, de acordo com a pesquisa, servir de suporte para as aulas e contribuir para o processo educativo. A formação de professores aparece, mais uma vez, como elemento chave para compreensão do tema.

A tese "A integração das tecnologias da informação e comunicação ao currículo no PROEJA", de Fernandes (2012), apresentada para obtenção do título de doutora pela PUC-SP, procura identificar caminhos para a utilização do potencial estratégico das TDIC, tendo em vista a construção do currículo integrado no âmbito do PROEJA Programa Nacional de Integração da Educação Profissional com a educação básica na modalidade da Educação de Jovens e Adultos. A autora procura investigar os documentos base do PROEJA e o plano de curso do PROEJA do Instituto Federal de Educação, Ciência e Tecnologia de São Paulo, com o objetivo de compreender os significados dados à potencialidade das TDIC na integração da educação profissional à educação de jovens e adultos no ensino médio. Além disso, a pesquisadora também procura estabelecer contato com seu corpus de investigação através de sua aproximação junto aos professores do curso tomado como objeto de análise. Seu objetivo foi de criar um contexto crítico colaborativo junto ao professor de informática e demais docentes com o objetivo de compreender os significados que atribuem ao potencial das TDIC e compartilhar novos significados da integração das TDIC no currículo do programa. Neste trabalho, há mais centralidade na relação entre o currículo e as TDIC e no sentido que os professores dão às tecnologias no currículo do programa investigado. De modo geral, a autora conclui que parte dos professores compreendem as TDIC a partir de uma perspectiva instrumental, o que impacta significativamente na constituição do currículo, e também exclama para a necessidade de se repensar a formação de professores para o uso pedagógico das TDIC. 
As tecnologias digitais da informação e da comunicação nos contexto da Educação de Jovens e Adultos: uma revisão de literatura (2007-2014)

Nos anais do VI Seminário Luso-Brasileiro - Educação, Trabalho e Movimentos Sociais, realizado em Lisboa, Portugal, Amparo et al. (2013) publicaram o trabalho "Inclusão digital na educação de jovens e adultos: uma análise em um município do Brasil”, cujo objetivo é apresentar os resultados de uma pesquisa exploratória, realizada no ano de 2012, que teve como intuito a identificação da existência de um trabalho que possa contribuir para a inclusão digital em salas de educação de jovens e adultos em um município do Brasil. Foram observadas quatro escolas por um período de quatro meses, além da realização de entrevistas com professores e estudantes. Os resultados finais, segundo os autores, apontam para uma situação preocupante: os professores das escolas investigadas não têm incitado qualquer processo de inclusão digital em suas aulas ou, quando há presença de tecnologias, ela se dá de forma mecanizada. A preocupação dos pesquisadores é com a reprodução do processo de exclusão digital. Em suma, os autores alertam também para a frágil formação para o uso das TDIC dos educadores que atuam nas escolas investigadas, na medida em que eles tinham amplas condições estruturais de promover o acesso dos estudantes à cultura digital.

No trabalho apresentado no Congresso Ibero-Americano de Ciência, Tecnologia, Inovação e Educação, em Buenos Aires, Cord e Melo (2014) relatam a experiência com a produção de conteúdo digital (vídeo), em uma turma de alfabetização na Educação de Jovens e Adultos (EJA) do município de Florianópolis, Santa Catarina. Em “A produção de conteúdo - vídeo - em Tecnologia Digital de Informação e Comunicação (TDIC): um recurso pedagógico no trabalho com uma turma de alfabetização da Educação de Jovens e Adultos", as autoras descrevem o trabalho pedagógico de produção de vídeo, cujo objetivo era convidar outras pessoas a retomar sua escolarização através da EJA, por estudantes da turma de alfabetização. O trabalho resultou em um processo pedagógico de construção de saberes e afirmação de identidades, com vistas ao exercício da cidadania. Segundo o estudo, o projeto também ratificou as potencialidades das TDIC, ao permitir a sujeitos em processo de alfabetização se (re)conhecerem como autores, criadores de um conteúdo inédito e tão importante para outras pessoas. A produção de conteúdo digital na EJA teria, segundo Cord e Melo (2014), a dupla função de ampliar as possibilidades de circulação dos próprios estudantes em um mundo letrado e altamente tecnologizado e também ampliar sua participação cidadã em uma sociedade cada vez mais crivada de processos de informação e comunicação. Concluem que é possível que sujeitos, como os estudantes em tela, pouco escolarizados e com pouquíssima experiência no uso de recursos das TDIC, possam assenhorar-se de todo o processo de produção e comunicação 
existente na produção de um vídeo e, assim, possibilitar a conquista de espaço para exercitar a cidadania.

\section{Aproximações e distanciamentos entre os estudos}

Diante deste quadro de artigos, dissertações e teses publicadas entre 2007 e 2014, que relacionam as TDIC com a educação de jovens e adultos, é possível observar algumas tendências deste novo campo de pesquisa. Entre as universidades de origem dos pesquisadores dos 14 estudos levantados nesta revisão de literatura, destacam-se o Centro Federal de Educação Tecnológica de Minas Gerais (CEFET-MG), onde foram produzidas quatro dissertações abrangidas no estudo, e a Universidade Federal da Bahia (UFBA), de onde se originam outros dois estudos. As demais produções são difusas, sendo cada uma delas de uma universidade pública (UFSCar, UTFPR, USP, UFAL, UNESP e UESC) ou comunitária (PUC-RS e PUC-SP).

A primeira tendência observada refere-se à escassez de trabalhos preocupados em investigar o impacto das tecnologias na EJA. Trabalhos como os de Coelho (2011), Hidalgo (2007), Nápoles (2008), Santos (2008) e Fernandes (2012), por exemplo, fazem críticas à secundarização do tema, tanto no campo de pesquisa em EJA, quanto no que se refere aos estudos acadêmicos sobre uso pedagógico das TDIC. Gontijo e Melo (2007) vão além, pois observam a marginalização da EJA nas políticas e nos estudos que visam à inserção das TDIC nas escolas e a marginalização das TDIC nas políticas e nos estudos voltados ao campo da EJA, no país. Estes dados são representativos de que não há ainda grande mobilização de pesquisadores do campo das tecnologias educacionais, para refletir sobre essa temática, no contexto específico da educação de adultos. Da mesma forma, a literatura é representativa de que também não é prioridade dos pesquisadores do campo da educação de jovens e adultos a investigação sobre os limites e as possibilidades do uso pedagógico das TDIC e da inclusão digital, nesta modalidade escolar.

A segunda tendência refere-se à percepção dos autores em relação à potencialidade do uso das TDIC na EJA, como contribuição ao processo de ensinoaprendizagem e como parte fundamental do processo de inclusão digital, que se apresenta como chave para a reflexão sobre o acesso da população economicamente desfavorecida à "vivência plena da cibercultura", na expressão de Bonilla (2010). Todos os autores partem da suposição de que ações que insiram pessoas jovens e adultas que retomam seu 
As tecnologias digitais da informação e da comunicação nos contexto da Educação de Jovens e Adultos: uma revisão de literatura (2007-2014)

processo de escolarização na cultura digital podem significar ganhos em sua aprendizagem e contribuir para seu empoderamento, na acepção freireana do termo.

A terceira percepção que se tem da análise da revisão destas pesquisas advém de seus resultados finais. Autores como Hidalgo (2007), Santos (2008), Cruz (2008), Nápoles (2008), Gontijo (2008), Flores (2011) e Fernandes (2012) criticam a perspectiva instrumental do uso das TDIC, por professores da EJA, observada em situações investigadas em suas pesquisas e apontam, insistentemente, para a necessidade de se repensar a formação de professores. Mais que uma tendência indicada por estas pesquisas, a formação de professores para uso pedagógico das TDIC consubstancia-se como uma demanda urgente.

Entre todos os trabalhos, os de Brito (2010) e de Coelho (2011) destacam-se, pela lucidez na análise da conjuntura da EJA no Brasil e por partirem do paradigma da educação ao longo da vida e da perspectiva da EJA como um direito. A primeira pesquisadora acredita na inspiração trazida por esta nova perspectiva de EJA, associada às possibilidades de "novas educações" que o uso das tecnologias pode trazer (BRITO, 2010). Na visão de Coelho (2011),

[...] o aluno da EJA está inserido nesse contexto digital que caracteriza a contemporaneidade e por isso precisa desenvolver habilidades e competências que o preparem para exercer um papel participativo nessa sociedade no exercício de sua cidadania. Uma educação de qualidade é o meio e a oportunidade para que ele ressignifique a sua história e tenha a possibilidade de interagir, conhecer, construir conhecimentos por meio das infinitas possibilidades da cibercultura, aumentando seu potencial de leitura e de reescrita de sua própria história (COELHO, 2011, p. 68).

Em conformidade com esta visão, Brito (2010) também defende a perspectiva da educação ao longo da vida, para quem "o investimento na criação e no incentivo de projetos e programas de EJA que atendam às recomendações e expectativas do paradigma da aprendizagem ao longo da vida parece urgente" (BRITO, 2010, p.87). Associada a esta perspectiva, a pesquisadora também sustenta a perspectiva da educação aberta, das comunidades de aprendizagem e da flexibilização dos currículos e métodos utilizados na educação de jovens e adultos. Este olhar indica uma visão que relaciona o direito à EJA com o direito à inclusão digital, como pressupostos fundamentais para o pleno exercício da cidadania. Os dois trabalhos, desta forma, apontam a tendência de superação do paradigma da educação compensatória na EJA e do paradigma do uso instrumental das TDIC. 
A perspectiva geral dos estudos acadêmicos selecionados nesta revisão aponta, portanto, para uma mudança de paradigma. Esta visão, quando ultrapassar os limites do discurso acadêmico, das políticas públicas e dos movimentos sociais e adentrar as práticas nas salas de aula da educação de jovens e adultos, poderá representar um novo momento para a EJA no Brasil, pautado por uma perspectiva de transformação social, através da emancipação individual e coletiva dos sujeitos da EJA, empoderando-os como atores sociais. Espera-se, portanto, que este estado da arte das pesquisas sobre o as TDIC na EJA possa contribuir para a construção paulatina de um conjunto de pesquisas que permita o diálogo entre os autores, as ideias e os desafios dos dois campos da pesquisa educacional.

\section{REFERÊNCIAS BIBLIOGRÁFICAS}

AMPARO, M. A. M.; SCHLÜNZEN JUNIOR, K.; FURLANETTI, M. P. de F. R. Inclusão digital na educação de jovens e adultos: uma análise em um município do Brasil. In: Atas do VI Seminário Luso-Brasileiro Educação, Trabalho e Movimentos Sociais, Lisboa, Portugal, 2013. p. 39-51.

ARROYO, M. G. Educação de jovens e adultos: um campo de direitos e responsabilidade pública. In: SOARES, L.; GIOVANETTI, M. A. G. de C.; GOMES, N. L. (orgs.) Diálogos na educação de jovens e adultos. Belo Horizonte, MG: Autêntica, 2005.

BELLONI, M. L. Tecnologia e formação de professores: rumo a uma pedagogia pósmoderna? In: Educ. Soc., v. 19, n. 65, Campinas, SP, dez. 1998. p. 143-162.

BRASIL. Lei de Diretrizes e Bases da Educação Nacional. Lei número 9394, 20 de dezembro de 1996.

BRITO, B. M. S. Jovens e Adultos em Processo de escolarização e as tecnologias digitais: quem usa, e a favor de quem e para quê? Dissertação (Mestrado em Educação) - Programa de Pós-Graduação em Educação, Faculdade de Educação, Universidade de São Paulo. São Paulo, 2010. 121f.

BRITO, G. A Inclusão Digital do Profissional Professor: entendendo o conceito de tecnologia. In: Anais do 30 ${ }^{\circ}$ Encontro Anual da ANPOCS: Associação Nacional de Pós-Graduação e Pesquisa em Comunicação Social, Caxambu, MG, out. 2006.

BONILLA, M. H. S. Políticas Públicas para Inclusão Digital nas Escolas. In: Revista Metrovivência, ano XXII, n. 34, UFSC, Florianópolis, SC, jun. 2010. p. 40-60

COELHO, L. A. As relações dos alunos da EJA com as tecnologias digitais: implicações e possibilidades na vida de cada um. Dissertação (Mestrado em Educação), 
Programa de Pós-Graduação em Educação, Faculdade de Educação, Universidade Federal da Bahia, Salvador, 2011. 133f.

CORD, D.; MELO, S. M. M. A produção de conteúdo - vídeo - em Tecnologia Digital de Informação e Comunicação (TDIC): um recurso pedagógico no trabalho com uma turma de alfabetização da Educação de Jovens e Adultos. In: Congresso Ibero-Americano de Ciência, Tecnologia, Inovação e Educação. Memorias del Congreso Iberoamericano de Ciencia, Tecnología, Innovación y Educación, Buenos Aires, Argentina, nov. 2014. p. 01-14.

CRUZ, R. M. R. Limites e possibilidades das tecnologias na educação de jovens e adultos. Dissertação (Mestrado em Educação Tecnológica), Programa de Pós Graduação em Educação tecnológica, Centro Federal de Educação Tecnológica de Minas Gerais, Belo Horizonte, MG, 2008. 185 f.

DI PIERRO, M. C. Notas sobre a redefinição da identidade e das políticas públicas de educação de jovens e adultos no Brasil. In: Educ. Soc., vol. 26, n. 92, Campinas, SP, 2005. p. 1115-1139.

FERNANDES, J. R. A integração das tecnologias da informação e comunicação ao currículo no PROEJA. Tese (Doutorado em Educação: Currículo), Programa de PósGraduação em Educação: Currículo, Pontifícia Universidade Católica de São Paulo, São Paulo, 2012. 329f.

FLÔRES, E. S. O uso da TV e do computador nas práticas docentes de Língua Portuguesa na educação de jovens e adultos. Dissertação (Mestrado em Educação Brasileira), Programa de Pós-Graduação em Educação, Centro de Educação, Universidade Federal de Alagoas, Maceió, AL, 2011. 150f.

FREIRE, P.; SHOR, I. Medo e Ousadia: o cotidiano do professor. Rio de Janeiro: Paz e Terra, $5^{\text {a }}$ edição, 1986.

FREITAS, M. C. de; BICCAS, M. de S. Educação de adolescentes, jovens e adultos analfabetos. In: FREITAS, M. C. de; BICCAS, M. de S. História social da educação no Brasil (1926-1996). São Paulo: Cortez Editora, 2009. p. 209-263.

GIROUX, H.. A. Os professores como intelectuais: rumo a uma pedagogia crítica da aprendizagem. Porto Alegre, RS: ArtMed, 1997.

GONÇALVES, B. H. O uso do computador, a alfabetização e a pós-alfabetização: o que dizem educandos/as do MOVA. Dissertação (Mestrado em Educação), Programa de PósGraduação em Educação, Centro de Educação e Ciências Humanas, Universidade Federal de São Carlos, São Carlos, SP, 2007. 172f.

GONTIJO, C. R. B. Tecnologias de informação e comunicação na educação de jovens e adultos. Dissertação (Mestrado em Educação Tecnológica), Programa de Pós- 
Graduação em Educação Tecnológica, Centro Federal de Educação Tecnológica de Minas Gerais, Belo Horizonte, 2008. $185 f$.

GONTIJO, C. R. B.; OLIVEIRA, M. R. N. S. Vozes docentes e discentes sobre condições, objetivos e contribuições do uso das TICs na EJA. In: Anais do I Seminário Nacional de Educação Profissional e Tecnológica. CD-ROOM, v.1, CEFET-MG, Belo Horizonte, MG, 2008.

GOULART, D. Inclusão digital na terceira idade: a virtualidade como objeto e reencantamento da aprendizagem. Dissertação (Mestrado em Educação), Programa de Pós-Graduação em Educação, Pontifícia Universidade Católica do Rio Grande do Sul, Porto Alegre, 2007. 196 p.

GOUVEA, A. B. Políticas e Financiamentos na EJA: as mudanças na política de financiamento da educação e possíveis efeitos na EJA. In: EcoS - Revista Científica, vol. 10, n. 2, São Paulo, 2008. p. 379-395

HADDAD, S.; DI PIERRO, M. C. Escolarização de jovens e adultos. In: Revista Brasileira de Educação, s/v, n.14, Rio de Janeiro, maio de 2000. p.108-130

HIDALGO, S. A educação de jovens e adultos no município de Curitiba sob a ótica de gênero e tecnologia. Dissertação (Mestrado em Tecnologia) - Universidade Tecnológica Federal do Paraná, Curitiba, PR, 2007. 197f.

LAVINAS, L.; VEIGA, A. Desafios do modelo brasileiro de inclusão digital pela escola. Cadernos de Pesquisa, vol. 43, n. 149, São Paulo, maio 2013. p.542-569.

NÁPOLES, N. N. O uso das tecnologias da informação e comunicação na educação de jovens e adultos: visão de alunos e professores de uma escola municipal de Belo Horizonte. Dissertação (Mestrado em Educação Tecnológica), Programa de Pósgraduação em Educação Tecnológica, Centro Federal de Educação Tecnológica de Minas Gerais, Belo Horizonte, MG, 2008. 123 f.

SANTOS, A. 'Tá vendo aquele edifício moço?' - A especificidade da inclusão digital para trabalhadores da construção civil não alfabetizados. Dissertação (Mestrado em Educação) - Programa de Pós-Graduação em Educação, Faculdade de Educação, Universidade Federal da Bahia, Salvador, 2008. 158f.

PESCE, L. Políticas de formação inicial de professores, tecnologias e a construção social do tempo. In: EcoS - Revista Científica. v. 33, n. 01, São Paulo, jan.- abr. 2014. p. 157172.

. O Programa um computador por aluno no estado de São Paulo: confrontos e avanços. Anais da $36^{\circ}$ Reunião Nacional da ANPEd, Goiânia, GO, 2013. 
RESENDE, M. A. Os saberes dos professores da Educação de Jovens e Adultos: o percurso de uma professora. Editora da UFGD, 1ª ed. Dourados, MS, 2008.

TORRES, R. M. Resumen ejecutivo. In: TORRES, R. M. (org.) Aprendizaje a lo largo de la vida. Bonn, Educación de Adultos y Desarrollo, Suplemento 60, Buenos Aires, Argentina, 2003. p. 17-30.

VALENTE, J. A. Uso da internet em sala de aula. In: Educar em Revista, s/v, n. 19, Curitiba, PR, 2002. p. 131-146.

Recebido em: 12/02/2016

Aprovado em: 25/04/2016 